\title{
Digitalization of Institutions of Corporate Law: Current Trends and Future Prospects
}

\author{
Vasiliy Andreevich Laptev (D) and Daria Rinatovna Feyzrakhmanova *(D) \\ Department of Entrepreneurial and Corporate Law, Kutafin Moscow State Law University, \\ 109180 Moscow, Russia; laptev.va@gmail.com \\ * Correspondence: daria.feyzrakhmanova@gmail.com
}

Citation: Laptev, Vasiliy Andreevich, and Daria Rinatovna

Feyzrakhmanova. 2021.

Digitalization of Institutions of

Corporate Law: Current Trends and

Future Prospects. Laws 10: 93.

https: / / doi.org/10.3390/

laws10040093

Received: 15 September 2021

Accepted: 28 November 2021

Published: 2 December 2021

Publisher's Note: MDPI stays neutral with regard to jurisdictional claims in published maps and institutional affiliations.

Copyright: (c) 2021 by the authors. Licensee MDPI, Basel, Switzerland. This article is an open access article distributed under the terms and conditions of the Creative Commons Attribution (CC BY) license (https:// creativecommons.org/licenses/by/ $4.0 /)$.

\begin{abstract}
Digital technologies have been integrated into all aspects of public life, including politics, law, finance, business, education, science, and society. As a result of the use of digital technologies by various subjects, a transformation has occurred of the economic relations existing in society, including corporate relations. This study analyzes the impact of digitalization on individual institutions of corporate law. The authors investigate the following aspects of the digitalization of corporate law: (1) digital legal personality of the corporation (online registration (e-residency) of corporations and the digital footprint that companies leave in public registers); (2) digital corporate governance; and (3) digital (network or decentralized) autonomous organizations. The purpose of this research is to identify trends and directions of transformation of individual institutions of corporate law in a digital society. The authors conclude that the digitalization of institutions of corporate law will result in: (1) the reinterpretation of certain concepts of corporate law, such as corporation and corporate governance; (2) the improvement of the legal mechanisms of corporate governance following the introduction of AI into the collegial executive bodies of corporations; (3) the digitalization of corporate assets; and (4) the emergence of new subjects of corporate and other relevant relations.
\end{abstract}

Keywords: corporation; e-residency; corporate governance; digital governance; artificial intelligence; decentralized autonomous organization

\section{Introduction}

The development of information technologies and their implementation into the daily life of modern individuals have marked the transition to an information society, digital economy and digitalization of different aspects of public life. Digitalization sweeping through the various sectors of public life currently represents one of the most popular research topics or, as some scholars refer to it, a megatrend (Vaypan 2017).

Digital technologies have been integrated into all aspects of public life, including politics, law, finance, business, education, science. Yet, digitalization exerts an even greater impact on the economy, which should prompt the State, represented by its legislative and executive bodies, to take timely action to ensure the legal regulation of diverse aspects of the digital economy.

Most efforts aimed at improving corporate legislation in the context of digitalization are currently focused on creating and promoting a digital environment that would ensure effective interaction between corporate actors and persons directly associated with them.

There are different opinions among scholars concerning which phenomena are encompassed by the digitalization of modern corporate law. For example, according to Oleg Gutnikov, this concept includes the adoption of digital technologies in corporate governance, the creation of novel types of digital legal entities and their online registration, the digitization of charters of commercial corporations and their inclusion in the Unified State Register of Legal Entities of Russia (Gutnikov and Sinitsyn 2019), and the tokenization of corporate assets (Gutnikov 2020). 
Yet, some researchers equate the digitalization of corporate law with the digitalization of corporate governance (i.e., the introduction of technologies enabling online general meetings, e-voting, automation powered by artificial intelligence (AI), etc.) (Vermeulen 2015; Yermack 2017; Charan 2011). However, in our opinion, the digitalization of corporate law is not limited to the digitalization of corporate governance, and may also include other aspects, for example, issues regarding the digital legal personalities of corporations, and the creation of decentralized autonomous organizations, which will be further discussed in this study.

The application of digital technologies for corporate governance and maintenance of electronic records increases the efficiency of corporations, optimizes their business processes and facilitates interactions among corporate members, as well as with third parties. However, as demonstrated by Ichak Adizes, corporations can benefit from the adoption of digital technologies throughout their entire life cycle (Adizes 2004). For example, such technologies can be used at the stage of creating a corporation and endowing it with legal personality.

Thus, it appears reasonable to include issues related to the digital legal personalities of corporations, digital corporate governance and the operations of digital corporations (networked and decentralized autonomous organizations) in discussions concerning the digitalization of corporate law.

The present work outlines the characteristics of corporate law in the age of the digital transformation of the Russian and foreign economies.

The remainder of the paper is organized as follows. Section 4 explains aspects of digital legal personality of a corporation (online registration (e-residency) of corporations and the digital footprint that companies leave in public registers). The problems of digitalization of corporate governance (distributed ledger technology (blockchain), e-voting, using videoconferencing at meetings and artificial intelligence (AI)) are described in Section 5. Section 6 contains information on decentralized autonomous organizations.

\section{Materials and Methods}

The research information base consists of 74 sources, including various regulatory legal acts on corporate law, research in the field of corporate law and digitalization of society, thematic publications in the media and Internet sources.

The methodological basis of the theoretical research was formed by general scientific methods of cognition, which include the principles of objectivity and system analysis of the information collected during preparation of the publication. At the same time, the authors used special legal methods, such as the formal interpretation of legal acts, comparative analyses of Russian and European legal literature, and the formal legal method, which made it possible to define and explore various concepts, and to highlight their signs.

\section{Literature Review}

Currently, digitalization of various spheres of public life is the most discussed topic of scientific research and, as scientists note, a megatrend (Vaypan 2017).

The issues of digitalization of certain aspects of corporate law were considered in the following studies. So, O.V. Gutnikov proposed a definition of digitalization of corporate law and disclosed its elements (Gutnikov and Sinitsyn 2019), and also considered the issues of tokenization of corporate assets (Gutnikov 2020).

Most of the scientific research is mainly devoted to the problems of digital corporate governance (Vermeulen 2015; Yermack 2017; Charan 2011; Adizes 2004; Charan 2011; Chekhovskaya 2018a; Fenwick and Vermeulen 2019; Gandía 2005; Yankovskiy and Yendutkin 2020). Research on digital corporate governance also summarizes the practice of using technologies such as e-voting (Gao et al. 2020; Mellon et al. 2017; Shukla et al. 2018; Trubochkina and Poliakov 2019), blockchain technology (Alekseev 2018; Egorova et al. 2019; Fenwick and Vermeulen 2019; Laptev 2019; Sannikova 2019; Yermack 2017), artificial intelligence (Cihon et al. 2021; Dignam 2020; Erel et al. 2018; Möslein 2018), etc. 
In addition, the authors also analyzed individual scientific studies on the functioning and practice of using blockchain technology and artificial intelligence in various spheres of public life (Beck 2018; Blemus 2017; Buterin 2014; De Filippi and Wright 2018; Dhillon et al. 2017; Domingos 2015; Feijóo et al. 2020; Fersht and Slaby 2012; Goertzel 2016; Hsieh et al. 2018; Polge et al. 2021).

The next group of studies is devoted to the problems of decentralized autonomous organizations, as well as the adaptation of the principles of corporate governance and corporate law to ensure the functioning of such digital systems (Faqir et al. 2020; Jentzsch 2017; Singh and Kim 2019; Chekhovskaya 2018b; Yankovskiy and Yendutkin 2020).

\section{Digital Legal Personality of a Corporation}

The establishment of an economic entity, the beginning of its lifecycle and the onset of its production activities and business operations are associated with the acquisition by it of legal personality (legal status), i.e., the ability to participate in entrepreneurial and other economic relations (Laptev 1969; Tolstoy 1959).

\subsection{Online Registration (E-Residency) of Corporations}

On 25 April 2018, the European Commission presented a package of proposals for reforming the EU legislation for companies with respect to the use of digital tools and processes in corporate law. These proposals were introduced to implement the Digital Single Market Strategy previously adopted by the European Commission, which provides for certain regulations enabling digital solutions for company registration, among other things.

These regulations primarily concern the implementation of online company registration that could be completed without contacting the relevant authorities or competent persons directly. The key benefit of online registration is accelerating the processes of creation and registration of companies, as Member States must ensure that online company registration is completed within five business days of the date on which the fee was paid or the date on which the complete application was submitted (whichever comes later).

On 20 June 2019, the European Parliament and the Council of the European Union ruled to amend the existing Directive (EU) 2017/1132 relating to certain aspects of company law by issuing Directive (EU) 2019/1151 that established specific rules concerning the online formation of companies, registration of branches, and filing of documents and information by companies and branches ('online procedures'). According to the provisions of this new Directive, Member States must establish the procedures for creating companies, registering branches and filing documents and information fully online. However, national legislations may provide for exceptions limiting the application of the online registration procedure to certain types of companies. Further, the provisions of this Directive prohibit Member States from enforcing any requirements to obtain a prior authorization or license for online company registration in their national legislations, unless it is necessary for ensuring a proper oversight of certain activities carried out by companies.

Notably, the online procedure of company registration does not preclude the involvement of notaries or lawyers who may verify the identity and legal capacity of persons intending to create a company, register a branch, or submit relevant documents or information to the authorities. However, such involvement should not prevent the completion of the procedure in its entirety online.

Estonia, which became the first country in the world to introduce international digital residency (e-residency) (The New Digital Nation n.d.), is a prime example. Digital technologies enable Estonian residents to vote online, fill out documents on the web, and register businesses remotely. An individual who signed up and received an ID in accordance with the established procedure can register and manage companies online from anywhere in the world, as well as use online banking services, declare assets online, sign documents and enter into contracts using an electronic digital signature. 
The implementation of digital residency in the Russian Federation would require amending the current legislation to enable online registration of organizations via the submission of an electronic form on the Common Government Services Portal ("GosUslugi").

It appears that the online registration procedure for national companies will provide efficiency, ease and cost reduction both for citizens of individual member states seeking to establish new companies in their country, and for citizens of other member states wishing to establish a company abroad.

\subsection{Digital Footprint of Companies in Public Registers}

In corporate practice, the legal personality of an organization is established by entering information about the new corporation or a corporation formed as a result of the reorganization of an existing corporation into the relevant state register by a competent government agency. In the Russian Federation, this registry is called the Unified State Register of Legal Entities, and its maintenance is entrusted to the tax authority (Resolution of the Government of the Russian Federation of 30 September 2004 No. 506 "On Approval of the Regulations on the Federal Tax Service").

Different countries and regions have their own commercial registers containing information on the legal status of companies with various forms of incorporation. For example, in April 2019, the European Union established the European Business Registry Association (EBRA) that manages the European Business Register Network (EBR), which provides consolidated information on companies operating in 22 European countries.

Different European states entrust the maintenance of their commercial registers to different public authorities. For example, in Austria such a register is maintained by authorized district courts (Republik Österreich Firmenbuch), in Germany-by the German Ministry of Justice and authorized district courts (Unternehmensregister), in Belgium-by the Federal Public Service Economy, in France-by authorized commercial courts (although the register is administered by a commercial company) (Infogreffe), etc.

The purpose of creating and maintaining commercial registers containing information on the juridical status of legal entities that are engaged in entrepreneurial and/or other economic activities in a given state is to provide legal certainty with respect to economic legal relations and economic transactions, as well as to ensure access to general information on the actual structure of legal entities.

The use of information contained in public registers is governed by the "public credibility" principle, according to which a person (e.g., a counterparty or a business partner of a company) that relies on the register records is presumed to be unaware of any potential inaccuracy contained in such records. This is further clarified by the Supreme Court of the Russian Federation (see Paragraph 22 of the Resolution of the Plenum of the Supreme Court of the Russian Federation No. 25 of 23 June 2015 “On the Application by the Courts of Certain Provisions of Section I of Part One of the Civil Code of the Russian Federation").

Certain information about the economic activities of legal entities can be found in other open sources. For example, the financial statements of Austrian companies are published on the website of the state-owned daily Wiener Zeitung, the accounting records of active Belgian companies, associations and foundations can be found on the website of the National Bank of Belgium, whereas the database of disqualified directors of British companies is made available on the Companies House website.

In the Russian Federation, material facts of corporations are subject to disclosure on the online portal "Center for the Disclosure of Corporate Information", administered by Interfax. Data subject to public disclosure include information about concluded transactions, securities issues, income payments, performance of obligations, decisions made by the governing body of an issuer (corporation), etc.

Information about special economic competences (a set of rights and obligations corresponding to the goals of the corporation's activities provided for in the constituent documents) of certain Russian legal entities is also maintained in public registers. For 
example, in the construction sector, such information is aggregated on the online portals of the National Association of Builders (https:/ / nostroy.ru/; accessed on 10 September 2021) and the National Association of Surveyors and Design Engineers (http://nopriz.ru/; accessed on 10 September 2021).

\section{Digital Corporate Governance}

There is no consensus on the definition of corporate governance among scholars of corporate law. Different academics have proposed corporate governance be defined as the structure of the bodies of a corporation and their respective competences (Sukhanov 2014), the process of identifying and regulating the focus areas of a corporation's activities, setting goals and establishing methods for their achievement (Lomakin 1997), the system of institutional and property relations, which enable a corporation to advance, represent and protect the interests of its investors and, most importantly, its shareholders (Dolinskaya 2006), the function of the governing body of a corporation to ensure the streamlining of its activities and the achievement of its goals (Kharitonova 2014).

We propose to define the concept of corporate governance as an umbrella term that covers several related phenomena, including:

the establishment in a corporation of the system of governing bodies;

the process of identifying and regulating the main areas of activities of a corporation, determining goals of these activities and methods for their achievement, as well as measures aimed at ensuring control over them (managing corporate activities);

a set of legal relations arising between the governing bodies of a corporation, its participants and other interested parties.

As noted above, digitalization is a current megatrend that encompasses all aspects of public life, including corporate governance. The implementation of digital technologies in corporate governance would make it possible to ensure the balance and protection of rights and interests of all participants in corporate and other relevant relations, increase the efficiency and transparency of a corporation, and promote competitiveness. Reducing cost, effort, time and resources are certainly among the main benefits of using digital technology in corporate governance.

Digital corporate governance refers to the process of managing the affairs of a corporation using existing digital technologies: electronic disclosure of information (Gandía 2005), electronic document management, participation in meetings via a recorded videoconference, remote e-voting on agenda items, and the use of artificial intelligence (AI) technologies in corporate governance (Feyzrakhmanova 2020a, 2020b).

Depending on the degree of human involvement in managerial decisions and the level of automation of management processes, three different types of digital corporate management (governance) can be identified: remote management (governance), smart management (governance) and AI management (governance).

Remote management (governance) involves the use of tools aimed at remote participation of a person (for example, a shareholder, CEO or member of the board of directors) in making and executing management decisions. Among the means of remote control can be distinguished, for example video conferencing, electronic voting.

Smart management (governance) in turn, is based on the use of tools for automatic control of a corporation according to pre-established algorithms without human intervention, but assuming the possibility of their correction and modification in the course of the program.

AI management (governance) (corporate management by AI) is the adoption by machine (AI) of managerial decisions that were not previously included in the program, excluding the human factor (cyber business companion). 


\subsection{Distributed Ledger Technology (Blockchain)}

A blockchain is an accessible, distributed database that stores information about all transactions made by its users (Egorova et al. 2019). In Russian jurisprudence, blockchains are also regarded as a valid method for the formalization of rights (Kharitonova 2018; Laptev 2018). As a result of the use of blockchain technology, it is possible to use an essentially digital certificate of authenticity, which provides a safe and efficient way to catalog intangible objects and rights to them, providing an undeniable record of registration of intellectual property rights, easily accessible from anywhere in the world.

The advantages of blockchain technology include decentralization, transparency, immutability and traceability of transactions. Therefore, the application of this technology in corporate governance can significantly increase its efficiency, as well as help promote the balance of interests of corporate members and protect their rights.

Blockchains can be public or private, with the only difference being who is eligible to participate in such a network. A public blockchain is available to everyone-anyone can join it by installing the appropriate software. Bitcoin is a prime example of a public blockchain (Náñez Alonso et al. 2021; Ammous 2018; Chowdhury 2019). This type of blockchain ensures the confidence of its users thanks to high accessibility and transparency of transactions. Any user can view the complete history of transactions and access their content, as well as carry out transactions through the use of smart contracts.

A closed blockchain makes it possible to selectively enter verified users, and thus, has a limited number of participants; for this reason, it is also sometimes referred to as permissioned blockchain (Polge et al. 2021). The main rationale for using a closed (private) blockchain is to ensure the confidentiality of data stored in such a registry.

Blockchains appear to be a promising tool for facilitating functions such as the maintenance of corporate registers, voting at general meetings, corporate control and auditing.

5.1.1. Maintaining the Register of Shareholders on a Blockchain Platform Is One of the First Steps toward the Implementation of Blockchain Technology in Corporate Governance

According to Paragraph 2 of Article 149 of the Civil Code of the Russian Federation, maintenance of the register of shareholders of a corporation can be entrusted solely to a registrar-a professional participant in the securities market, licensed to carry out activities for register maintenance (Article 44 of Federal Law No. 208-FZ of 24 November 1995 “On Joint-Stock Companies" (hereinafter referred to as the Joint-Stock Companies Law), Article 8 of Federal Law No. 39-FZ of 22 April 1996 "On Securities Market" (hereinafter referred to as the Securities Market Law)). These activities are carried out in the manner prescribed by the acts issued by the Bank of Russia.

In connection with the adoption of Federal Law No. 259-FZ “On Digital Financial Assets, Digital Currency and on Amendments to Certain Legislative Acts of the Russian Federation", from 1 January 2021, securities includes collecting, fixing, processing, storing not only data that make up the register of securities holders, but also data that make up the register of shares of a nonpublic joint stock company in the form of digital financial assets, as well as providing information from such registers.

The legislation prescribes that registers of corporate rights maintained in electronic form shall reflect all records related to personal and other accounts, as well as entries made into accounting books, transaction logs and document filing systems (Paragraph 4.1 of Regulation No. 572-P "On the Requirements for Keeping the Register of Securities Holders" approved by the Bank of Russia on 27 December 2016, hereinafter referred to as the Regulation).

In order to ensure data safety, the registrar is obliged to back up registration records on a daily basis to electronic, optical or other storage media that do not rely on the software used for processing these records (Paragraph 4.5 of the Regulation).

As a general rule, a transaction is recorded in the register on the day the required documents are received by the registrar, on condition they were submitted during office hours; alternatively, the record is made by the registrar no later than the next working day 
(Paragraph 2.2 of the Regulation). Thus, information on the transfer of stock ownership could take a relatively long time to be updated, resulting in legal uncertainty.

In contrast, transactions carried out via blockchain are processed much faster, allowing shareholders to exercise control over their stock in real time, which promotes the equality of shareholders' rights and reduces the incidence of corporate conflicts. Transactions are being recorded in the register uninterruptedly, $24 \mathrm{~h}$ a day, regardless of which country, time zone, etc. they are executed in.

For example, under Delaware law, books and records of a corporation can be stored on any device in the form of one or more electronic distributed ledger networks or databases. The main purpose of the adoption of this law was to provide companies with the ability to authorize and distribute their shares directly to investors via the Internet. It is mandatory that such records can be easily converted into paper format at the request of any person who has the right to inspect them, adding to their evidentiary value (Sannikova 2019).

In our opinion, it seems justified to entrust the maintenance of the register of shareholders to AI operating on the basis of a digital program (e-reestr) (Laptev 2019), which will operate on the blockchain platform, which would automatically record transactions while ensuring their confidentiality and preventing the risk of this information being used by a registrar, its employees or third parties acting in their own interests. We believe that the implementation of such a software program would make the maintenance of a register of shareholders more efficient, and would help safeguard the rights and legal interests of shareholders.

In addition, maintaining a shareholder register on the blockchain platform will increase the transparency of shareholding, which will also lead to more effective antimoney laundering and antiterrorist financing measures.

One example of how blockchain technology can be used for maintaining a register of shareholders is the Titan blockchain —a joint effort of Russian registrars started in 2018which facilitates transfer-agent services by automating the transfer of documents between registrars and eliminating manual processing of incoming documents. At present, all the largest registrars of Russia are using the Titan system, including such companies as Novyi Registrator, Status, IRC-R.O.S.T., VTB Registrar, Reestr, RNR Agency, VRK, RDC Paritet, Reestr-RN, SRK, Servis-Reestr and KRC. The system is available in 75 regions and is used by more than 3000 joint-stock companies.

Since, according to the current legislation, blockchain technology can be used for maintaining registers of shareholders only by registrars and professional participants in the securities market (but not by corporations themselves), the Titan blockchain platform represents a permissioned blockchain. It demonstrates that the procedure for maintaining registers of shareholders currently adopted in Russia is at odds with the very idea of the blockchain, that is, eliminating the middleman from register maintenance.

It is worth noting that most corporate disputes considered by arbitration courts, in one way or another, arise due to the imperfection of an existing mechanism for documenting corporate rights by companies. To address this issue, we suggest amending the current legislation to allow titles to securities to be documented using one or more electronic distributed ledger networks or databases (i.e., a blockchain) without involving a registrar.

By leveraging blockchain technology for maintenance of corporate registers, companies would be able to cut out intermediaries, such as registrars, reduce the costs associated with maintaining a register, and enhance trust between the issuer and shareholders.

It seems that in the near future, the legal community will need to explore new ways to protect rights to assets in digital form. For example, if person loses their password and/or access to a digital wallet (personal account) in the e-reestr, where the shares of the issuer belonging to its owner are taken into account, the question arises: who should act as an obligated person (respondent) if it is impossible to recover that information for any reason? In this case, the person administering the e-reestr and other shareholders did not violate the rights of the person who lost control of their assets. The following variable approach is proposed. First, it is possible to establish the procedure for recovering the beneficiary's 
access password to personal account. Secondly, if digital shares are not claimed and their owner does not participate in the management of the company, for example, for more than two years, these shares become the property of the issuer for their subsequent sale (or redemption) no later than one year from the date of their acquisition by the issuer.

5.1.2. Using Blockchain to Hold General Meetings of Shareholders. The Main Purpose of Introducing Blockchain Technology into the Voting Process Is Facilitating the Involvement of Corporate Participants in Governing a Corporation, and Reducing the Costs Associated with Organizing General Meetings

Unlike the traditional form of voting, voting on a blockchain platform does not require shareholders to be physically present in a meeting; instead, they can take part remotely by using their personal online account. Applied to voting, blockchains would allow every shareholder to verify, in real time whether, their vote had been accounted for, thereby ensuring the immutability of voting results.

The voting process on a blockchain platform can be implemented as follows: first, the question put to the vote is uploaded to the blockchain; next, members of the corporation are notified of when they can submit their vote remotely; immediately before the vote, tokens ("voting coins"), distributed between shareholders in accordance with the amount of stock they have in the corporation, are transferred to their electronic wallets; finally, these tokens are forwarded by shareholders to other electronic wallets, corresponding to the votes "in favor", "against", or "abstained" respectively.

Blockchain technology has already been introduced into corporate governance by several companies. For example, the first electronic voting via a blockchain platform was conducted by the U.S. company Nasdaq, which in 2017 began implementing it in Estonia (Estonian Trade Development Agency) and South Africa (Nasdaq to Deliver Blockchain E-voting Solution to Nasdaq to Deliver Blockchain E-voting Solution to Strate 2017).

In December 2017, American Stock Transfer \& Trust Company, LLC (AST) presented a pilot of its own blockchain-based e-service for shareholders (Longe 2017). The large-scale trial project involved more than eight million shareholders, jointly holding more than one trillion shares, and transactions were processed at a speed of over a hundred transactions per second.

In Russia, electronic voting can be conducted on a blockchain platform provided by the National Settlement Depository. E-voting is enabled by the Hyperledger Fabric framework, which ensures the safe processing of interactions between securities holders and issuers during the exchange of information at annual meetings of securities holders.

A blockchain system for remote corporate voting developed by the Distributed Ledger Technologies Center of St. Petersburg State University deserves a mention (A System of Blockchain Remote Voting is Developed at St. Petersburg University 2020). The CryptoVeche app for corporate voting, accessible both from smartphones and desktop browsers, can be used in any situations that require a trusted and secure voting environment. The application enables the registration of votes using smart contracts, ensures automatic vote count, and guarantees confidentiality and security throughout the entire voting cycle.

Larisa Sannikova believes that using blockchain with the sole purpose of enabling the remote submission of votes is not advisable, since it does not fulfill the primary objective of this technology, that is, ensuring the openness and transparency of transactions (Sannikova 2019). As advised by Sannikova, the application of blockchain technology to facilitate this aspect of corporate governance is appropriate only if information about all votes, rather than limited information about a vote submitted by a given corporate member, is available to all shareholders (members) of a corporation.

We believe that the implementation of blockchain technology in electronic voting would improve the mechanisms of corporate governance by enabling an efficient, trustworthy, immutable and verifiable voting system that would give rise to transparent and efficient interactions between a company and its shareholders.

Summing up the consideration of the aspects of the possible use of blockchain technology in corporate governance, it should be noted that the blockchain is a very promising 
technology; however, compared to other digital technologies used in corporate governance, it is difficult to use. Nonetheless, many states have already begun to adapt their legislation to support the use of blockchain technology in various fields. Thus, new legislative acts and draft amendments to existing laws have been adopted in several states such as Switzerland, Liechtenstein, Malta, France, Great Britain, Japan, Hong Kong and several US states (Blockchain Laws and Regulations 2020).

As part of the legal regulation of corporate governance, it is possible to propose amendments to the current legislation of the state that allow and establish certain rules for the use of blockchain technology for maintaining the register of shareholders of a corporation, as well as when ensuring electronic voting in large public corporations.

\subsection{E-Voting}

The term e-voting was first used in the middle of the last century to refer to the voting of citizens-voters using electronic means rather than paper ballots.

Currently, there is a lot of scientific research on various issues of e-voting. Thus, all research in this area can be divided into the following groups:

(1) the practice of using electronic voting in elections to state bodies (Russian and foreign experience) (Mellon et al. 2017; Toots et al. 2016; Alekseev 2018);

(2) the technological features of electronic voting (Yang et al. 2018; Shukla et al. 2018; Trubochkina and Poliakov 2019)

(3) on holding meetings of shareholders and boards of directors by means of electronic voting (Fontenot 2018; Chekhovskaya 2018a);

(4) the introduction of information technologies into the practice of holding general meetings of shareholders of foreign and Russian corporations in terms of agency costs, reducing the number of intermediaries between a shareholder and a company, and influencing the activity of investors (Gao et al. 2020; Sharma et al. 2018; Zamir et al. 2019).

Within the framework of this study, it is proposed to analyze the use of electronic voting technology in corporate governance.

E-voting can be divided into two types:

- $\quad$ stationary e-voting, in which the expression of the will of the participant is carried out with the help of technical means located in the places where general meetings are held;

- remote e-voting, in which the expression of the will of a participant is carried out using technical means that are located outside the places of holding general meetings.

Thus, we can conclude that e-voting in corporate governance means voting in which the expression of will is carried out by a participant using the technical means used for transmitting and counting votes.

Within the framework of this study, it is proposed to pay special attention to remote e-voting.

An e-voting service is a convenient tool for voting at general meetings by corporate members, allowing them to register for meetings, vote by submitting an electronic ballot form online, follow live-streamed broadcasts of meetings, and get acquainted with the agenda and related documents by accessing their verified accounts on the Common Government Services through remote authentication (in Russia for example Portal "GosUslugi").

As noted above, e-voting can be carried out with or without the help of distributed ledgers. Russian registrars, such as VTB Registrar, Reestr, Novyi Registrator, etc., offer platforms for e-voting, which are not powered by distributed ledger technology. According to the public information available, the platform provided by VTB Registrar was used to host 223 meetings that involved electronic voting of shareholders in 2020, and 94 such meetings in the first half of 2021 (VTB Registar 2021).

The VTB Registrar implemented the Meeting Portal, through which shareholders can access the Electronic Voting system using their personal accounts. In addition, in November 
2017, the VTB Registrar released a free smartphone app called Quorum, which allows its users to vote at general meetings of shareholders, as well as meetings of LLC and HOA members, meetings of the board of directors (supervisory board), management board, committees, forums, conferences and other events where voting is required. It should be noted that the largest Russian corporations, including Sberbank, Gazprom Neft and Moscow Exchange, among others, have already introduced electronic voting systems.

In the U.S., decisions on the format of shareholder meetings are adopted at the state level. The first electronic voting was held by Intel in 2009, and other players of the IT and telecommunications market followed suit. Meanwhile, in Turkey, for example, electronic voting at meetings of shareholders of public companies has been mandatory since 2012 (Turkish Commercial Code (Law No. 6102 dated 13 January 2011)).

One of the main advantages of e-voting is that it can easily be used by all members of a corporation, who access the electronic platform on which e-voting takes place through a web link or in an application. Authentication of shareholders (participants) in the electronic voting system can be carried out in one of the following ways: using an account on the Common Government Services Portal, using a nonqualified electronic signature, using dedicated user credentials, or using a qualified electronic signature. After identification, a participant creates a personal account on the platform where e-voting will take place. In the personal account, a shareholder (participant) can view the documents related to the upcoming voting, vote in favor of a particular decision, and learn about the voting results, all while doing so from any place in the world.

The use of e-voting increases the involvement of shareholders (participants) in the voting process, thus facilitating the achievement of quorum, fast-tracks the processing and counting of votes, prevents counting errors and precludes interference by third parties during vote count.

It seems that an electronic (online) voting system should meet the following conditions:

(1) only persons authorized to take part in the meeting and vote on the agenda items can take part in such voting (compliance with the specified condition is possible by identifying the meeting participant);

(2) the expression of will can be done only once;

(3) information on the expression of the will of each participant in the meeting is confidential (the e-voting system must ensure the safety of the specified data);

(4) the participants should not have the opportunity to receive intermediate voting results.

We believe that it is possible to extend the electronic voting procedure used at general meetings of corporate participants to all other meetings requiring collective decisionmaking, for example, to adopt it during voting of members of the board of directors, etc.

In summary, it should be noted that e-voting services are an important component in the formation of the digital ecosystem. Corporations that provide investors and shareholders with the opportunity to participate in meetings using digital services will be able to attract additional investment, providing a competitive advantage over other market participants.

\subsection{Using Videoconferencing at Meetings}

In the context of the recent restrictive measures introduced to counter the spread of the novel coronavirus infection (COVID-19), the issue of moving general meetings of corporate participants to a remote format with the help of videoconferencing has become particularly urgent.

Videoconferencing can be effectively used to host various meetings and sessions, including:

general meetings of shareholders (company participants),

meetings of the board of directors,

meetings of the collegial executive bodies (management board, directorate),

meetings of the heads of the parent and subsidiary companies, 
other intra-corporate meetings and sessions.

The existing Russian corporate legislation provides for the use of digital technologies for organizing general meetings of shareholders, participants in limited liability companies and members of noncommercial organizations (Paragraph 1 of Article 181.2 of the Civil Code of the Russian Federation Part One No. 51-FZ of 30 November 1994, Paragraph 11 of Article 49 of Federal Law No. 208-FZ of 26 December 1995 On the Joint-Stock Companies, Paragraph 1 of Article 38 of Federal Law No. 14-FZ of 8 February 1998 On Limited Liability Companies, Paragraph 4.1 of Article 29 of Federal Law No. 7-FZ of 12 January 1996 On Non-Profit Organisations). The current corporate legislation does not prohibit the use of digital technologies for remote participation by individuals in general meetings of the governing bodies of corporations, which is supported by the judicial practice.

To counter the spread of COVID-19, the Bank of Russia has recommended that jointstock companies allow their shareholders to remotely participate in the annual meeting by means of electronic voting, mailing in their ballot, submitting an electronic ballot online, etc. (Information Letter of the Bank of Russia No. IN-06-28/48 of 3 April 2020 "On Holding General Meetings of Shareholders in 2020"). However, most forms of remote participation in general meetings of shareholders proposed by the Bank of Russia represent participation in absentia, as they do not allow a shareholder to affect the decisions of other participants in a meeting (by addressing the meeting, participating in the discussion, etc.).

Holding remote, face-to-face general meetings via videoconferencing would allow corporate participants not only to make decisions and express their will by means of voting, but also to help other meeting participants make decisions.

Thus, it can be noted that the main difference between the remote general meeting of corporation participants and the electronic voting procedure is that a participant can take part in shaping the will of other corporation participants by discussing the issues on the agenda of the meeting, during which each participant will be able to present his or her own professional and reasoned opinion on a complex or controversial issue.

It seems that a general meeting of participants in a corporation that is held remotely by means of videoconferencing would be valid only if the following requirements are met: authentication of persons participating in the meeting, uninterrupted broadcasting, the possibility of documenting decisions made at the meeting in electronic form, and respecting the interests of all participants.

In the context of the ongoing pandemic, the use of videoconferencing technology in corporate governance is both an urgent and a forward-looking solution for interaction between corporate members both in Russia and abroad. In the U.S., Starbucks Corporation held the first fully virtual meeting of shareholders in March 2020 (Starbucks Will Host the Annual Meeting of Shareholders Virtually Because of Coronavirus 2020). The meeting was hosted on the Virtual Shareholder Meeting platform, which allows shareholders to directly participate in a meeting and vote on the issues included in the agenda (Virtual Shareholder Meeting, Broadridge 2021).

On 18 March 2020, the Italian government enacted a new decree that provided measures to support businesses and families during the COVID-19 pandemic (COVID-19: "Cura Italia" Decree Enacted 2020). According to this decree, in 2020, all general meetings of participants in corporations were to be held remotely, either by means of videoconferencing and electronic voting - on condition of authentication of the participants, their effective participation and guaranteed right to vote-or by means of absentee voting. However, the secretary or notary responsible for supervising the meeting and drawing up the minutes, together with the person(s) acting as the vote counting committee, were to be present at the meeting venue (listed in the notification of the meeting).

\subsection{Artificial Intelligence (AI)}

According to a survey of 200 business leaders and IT professionals undertaken by Gartner in late 2020, 24\% of organizations increased their investments in AI during the COVID-19 pandemic, whereas $42 \%$ of companies maintained their investments at the 
same level. This trend indicates that the market of traditional management tools has been saturated, and the economy needs a new source of demand.

$\mathrm{AI}$ represents a set of technological solutions that simulate human cognitive functions (including the abilities of independent learning and decision making in the absence of a predetermined algorithm) and that, when applied to certain tasks, can produce results that are comparable or better than those achieved by human intellectual activity. This set of technological solutions includes information and communication infrastructure, software (including applications that employ machine learning methods), data processing and decision-making services and tools.

The following types of AI are distinguished in the scientific literature:

(1) robotic process automation - the automation of basic human tasks such as creation of reports, etc. (Fersht and Slaby 2012);

(2) machine learning - the automation of decision-making, often without human intervention (Arrieta et al. 2020);

(3) AI approximating human behavior-so called artificial general intelligence or "strong" AI (Franklin 2007; Goertzel 2016).

Currently strong' or 'general' AI does not exist in practice (Feijóo et al. 2020; Dignam 2020; Domingos 2015).

Also in the doctrine, in addition to the concept of AI, there is the concept AI system lifecycle, i.e., the sequence of activities that take an AI system from its initial conception to its final use (Cihon et al. 2021). Attention to the lifecycle can help identify and clarify opportunities to improve AI corporate governance. Different actors and activities will have varying influence over different phases of the AI system lifecycle within a corporation.

The main advantage of $\mathrm{AI}$ is its ability to analyze large datasets in a short time and at a low cost. As part of corporate governance, the use of AI technology can reduce agency costs (Fenwick and Vermeulen 2019) by automating decision-making through real-time Big Data analysis (Moll and Yigitbasioglu 2019).

The use of AI technology in corporate governance seems to be justified in the following areas:

- $\quad$ ensuring the provision of reliable information to the members of the corporation and the board of directors through the analysis of a large amount of data (audit);

- automation of the functions of the sole executive body of the corporation and the board of directors (for example, automation of the procedure for selecting members of the board of directors (Erel et al. 2018; Danaher et al. 2017)).

Introduced into corporate governance, AI could be tasked with processing large amounts of information and assessing possible risks associated with strategically important decisions made on behalf of a corporation by members of its board of directors regarding the approval of transactions, etc., safeguarding against errors which could weaken the financial stability of the corporation or even lead to its bankruptcy (Möslein 2018).

In 2014, the Hong Kong-based venture capital fund Deep Knowledge Ventures, specializing in longevity technologies, appointed a self-learning software tool called VITAL (Validating Investment Tool for Advancing Life Sciences) to its board of directors. This tool was designed to analyze the financial performance of healthcare start-ups that the Hong Kong firm considered investing in. Although VITAL was granted "the right to vote" on whether or not to invest in a given project, it was not given the director status in the legal sense (Deep Knowledge Ventures: Redefining Investment 2021).

Project performance was evaluated both by board members and by the AI algorithm. If their assessments coincided, the firm would get involved in the project; if the assessments differed, the project performance was re-evaluated with due account of the new information provided by the AI, and the voting procedure was repeated until an agreement could be reached.

The current legislation provides no clarity with respect to whether AI is subject to the law and whether it should be held legally liable for its actions, which raises a pragmatic 
question: to what extent should the members of the board of directors be accountable for decisions made by AI?

When determining the extent of liability of board members for an erroneous decision based on the judgements of AI technology, it is first necessary to determine if technical failure or a software bug led to such a decision. It appears reasonable and justified to impose liability on the developers of AI systems for errors committed by such systems. Thus, in the event of technical failure or a software error in AI, board members should be exempted from liability for the decision based on the judgement of AI. Alternatively, members of the governing body should be held liable for damages caused to the corporation on general grounds.

Examples of AI-powered corporate governance tools include Cloverleaf and PineStem. Cloverleaf helps a project manager form a cohesive and efficient team to achieve specific goals and objectives by matching project team members on their skills and personal qualities, thus complementing the functions of an HR specialist (Cloverleaf: Coaching for Everyone 2021).

PineStem offers similar functionality, but in addition to assisting in building teams for specific projects, it also takes on the functions of tracking project progress, providing daily activity reports to team members and evaluating performance of teams.

\section{Virtual Assistants}

In Early 2017, Allan Rocha and Ricardo Vargas Presented the Virtual Assistant Service PMOtto-A Chatbot that Interacts with Project and Portfolio Management Systems, such as Microsoft Office 365 Project Online. This Program Converts Speech and Text into Program Commands, as well as Offers Recommendations Regarding Project Implementation, Based on Machine Learning Algorithms. A Similar Service Called Lili.ai Was Developed by French Software Engineers (Lili.ai)

In Russia, in 2018, the Distance Learning Center of the Project Practice Company Group presented the prototype of the Telegram chatbot called "Ivan from Project Practice" (@ivanpm_bot) (Meet the Chat Bot Ivan from Project Practice 2018)—a virtual assistant, which provided templates for project documents upon user request.

The intelligent digital assistant Construction IQ (Announcing Construction IQ Preview, Partner Data Integrations and Other Analytics Capabilities for BIM 360 2019) launched by Autodesk uses machine learning to analyze the quality and safety of construction projects and assess related project risks. The goal of this software is to provide its users with a report that would help them make appropriate management decisions.

The presented list of AI-powered virtual assistants is far from being exhaustive. The following applications of AI look particularly promising:

establishing and predicting the prices of goods;

addressing the staffing needs of a company;

distributing the competencies among the participants in corporate relations and corporate entities;

investing in the development of future products;

intra-departmental logistics, etc.

Thus, it can be noted that $\mathrm{AI}$ in its various forms opens up great potential for improving corporate governance mechanisms.

As a result of the automation of the processes of analyzing a large amount of data, the corporation participants will make more reasonable management decisions that take into account all kinds of risks. In addition, the use of AI in the selection of candidates for board members will also help reduce the risk of a conflict of interest, as well as the appointment of an incompetent director, since AI will objectively assess the competence of the candidate.

Along with the benefits of introducing AI into corporate governance, there are a number of challenges and risks. So, due to the fact that neural networks require a large amount of data to work effectively, when using AI technologies, a company will be forced to share 
information about its activities with a technology provider acting as an executor. Despite the self-learning of algorithms, the design and control of the operation of information systems based on AI in the future will be carried out by qualified specialists from highly specialized organizations.

Since the amount of information used and analyzed by AI is directly proportional to the degree of implementation of AI algorithms in the company's business operations, the company faces the risk associated with the disclosure of confidential business information of the corporation. Under these circumstances, it is important to develop appropriate rules aimed at protecting the confidentiality of information used by AI.

\section{Decentralized Autonomous Organizations}

The process of digitalization of the economy changes the organizational structure of corporations, which in its turn leads to the emergence of new participants in corporate relations.

The existing technology already makes it possible to create so-called decentralized autonomous corporations, which are governed on the basis of self-executing smart contracts (Blemus 2017). Such an organization can either be instituted within an existing corporation or established as a digital quasi-corporation, in which all processes, including management and interaction between participants (members), are decentralized and automated (Chekhovskaya 2018b).

Currently, there is no universal definition of a decentralized autonomous organization in the scientific literature. Buterin explains DAOs as a way to explore the governance rules of new organizations that could be automated and transparently embedded in a blockchain (Buterin 2014). Alternatively, Dhillon et al. define it as a blockchain entity built on a consensus of decisions by its members (Dhillon et al. 2017), while Beck et al. define it as a decentralized, transparent, and secure system for operation and governance among independent participants which can run autonomously (Beck et al. 2018). DAOs are virtual, decentralized entities such as corporations and institutions running entirely autonomously and decentralized on a distributed ledger (Singh and Kim 2019).

In essence, a decentralized organization is a company that is managed without human involvement, on the basis of automatically executed business rules generated by specialized software. Through the use of smart contracts, token holders (participants in a decentralized autonomous organization) manage the organization's assets, distribute profits, get notified about corporate activities, etc. In addition, through voting, participants can modify smart contracts that govern the decentralized organization. Thus, it can be concluded that a decentralized autonomous organization represents a digital counterpart to a traditional organization, which is based on smart contracts and tokens instead of constituent documents and stock.

In a decentralized autonomous organization, there is no owner or central governing body. The management of a decentralized autonomous organization is carried out by a group of people united by a common goal-miners who keep the system running.

Based on the results of the analysis of the provisions of the modern doctrine of decentralized autonomous organizations, the authors propose to highlight the following distinctive features of such organizations:

- $\quad$ ensuring coordination between people and self-government in the network (Yankovskiy and Yendutkin 2020; Singh and Kim 2019);

- the action of a decentralized autonomous organization is based on the smart contract code, which defines the rules of conduct for participants (De Filippi and Wright 2018); independence of management (Hsieh et al. 2018);

- $\quad$ transparency, cryptographic security and decentralization (Beck 2018).

The DAO investment fund was the first decentralized autonomous organization to be managed by its members through smart contracts (Jentzsch 2017). Numerous investors could directly invest the funds and get revenue from this activity. However, the smart contracts based on which The DAO operated contained a number of security vulnerabilities 
that allowed attackers to siphon off almost one third of The DAO's funds to a subsidiary account in a single day, which eventually led to the fund being shut down. Since then, the concept of a decentralized organization has been implemented in a number of other projects, including DAO House, DAOstack, Colony and Moloch DAO (Faqir et al. 2020).

The use of distributed ledgers and smart contracts is the main advantage of decentralized autonomous organizations, as they enable the participants in such organizations to take part in management decisions, and ensure the transparency of voting and vote count. Participants in decentralized autonomous organizations can directly manage and control its assets, which substantially simplifies the process of corporate governance. Some researchers have argued that direct corporate management and control over decision-making exercised by participants in direct autonomous organizations give rise to corporate selfgovernance, since these activities are carried out without the involvement of intermediaries, such as an executive body or a supervisory board (Yankovskiy and Yendutkin 2020).

The disadvantages of decentralized autonomous organizations operating through distributed ledgers include difficulties with prompt resolution of errors in smart contracts, importing data from third parties and maintaining the confidentiality within the organization, as well as the pressure exerted on the cryptocurrency market by financial regulators.

\section{Results}

According to the results of a scientific analysis of the problems of digitalization of individual institutions of corporate law, the authors:

(1) substantiated the distinction between the categories "digitalization of corporate governance" and "digitalization of corporate law". Considering that the use of digital technologies is possible throughout the entire life cycle of a corporation, the authors came to the conclusion that the concept of digitalization of corporate law includes, in addition to aspects of digitalization of corporate governance, issues related to the digital legal personality of a corporation, as well as the activities of digital (network or decentralized autonomous organizations) corporations;

(2) proposed to divide digital corporate governance into three types, depending on the degree of human involvement in managerial decisions and the level of automation of management processes:

- remote management (governance) involves the use of tools aimed at remote participation of a person (for example, a shareholder, CEO or member of the board of directors) in making and executing management decisions. Among the means of remote control can be distinguished, for example video conferencing, electronic voting;

- smart management (governance) in turn, is based on the use of tools for automatic control of a corporation according to pre-established algorithms without human intervention, but assuming the possibility of their correction and modification in the course of the program;

- $\quad$ AI management (governance) (corporate management by AI) is the adoption by machine (AI) of managerial decisions that were not previously included in the program, excluding the human factor (cyber business companion);

(3) concluded that it is expedient to place responsibility for the maintenance of the register of shareholders on artificial intelligence operating on the basis of a digital program (ereestr), which will operate on the blockchain platform, in order to automatically record transactions and ensure the confidentiality of information and exclude the possibility of using this information in their own interests by the holder registry, its employees and third parties. This program can work on the principle of a smart contract-an agreement in electronic form, the fulfillment of rights and obligations under which is carried out by automatic execution of digital transactions in a distributed ledger of digital transactions in a strictly defined sequence of such an agreement and upon the occurrence of certain circumstances. 
The authors also noted that maintaining a register of shareholders on the blockchain platform will help increase the transparency of shareholding, which will additionally lead to an increase in the effectiveness of measures to combat money laundering and terrorist financing. Blockchain technology will make it possible to reflect a sequential chain of transfer of rights to the issuer's shares. Hash blocks contain data on the transfer of ownership among all previous participants in transactions. Blockchain technology and a distributed ledger by themselves do not require additional protection and storage of accounts, since they already provide the highest technological protection for data on transactions and shareholders of the issuer;

(4) proposed to amend the current legislation of states to allow and establish certain rules for the use of blockchain technology for maintaining the register of shareholders of a corporation, as well as when ensuring electronic voting in large public corporations;

(5) as a result of the analysis, the following requirements are highlighted to which the electronic voting procedure must meet:

- only persons authorized to take part in the meeting and vote on the agenda items can take part in such voting (compliance with the specified condition is possible by identifying the meeting participant);

- the expression of will can be done only once;

- information on the expression of the will of each participant in the meeting is confidential (the e-voting system must ensure the safety of the specified data);

- the participants should not have the opportunity to receive intermediate voting results.

(6) argued that the main difference between the remote general meeting of corporation participants and the electronic voting procedure is that a participant can take part in shaping the will of other corporation participants by discussing issues included in the agenda of the meeting, during which each participant will be able to present his professional and reasoned opinion on a complex, controversial or controversial issue;

(7) noted that the use of AI when selecting candidates for members of the board of directors will also help reduce the risk of a conflict of interest, as well as the appointment of an incompetent director, since AI will objectively assess the competence of the candidate;

(8) revealed the following distinctive features of decentralized autonomous organizations:

- $\quad$ ensuring coordination between people and self-government in the network;

- the action of a decentralized autonomous organization is based on the smart contract code, which defines the rules of conduct for participants;

- independence of management;

- transparency, cryptographic security and decentralization.

\section{Conclusions}

The reviewed digital aspects of legal personality of corporations, corporate governance and the operation of decentralized autonomous organizations attest to the rapid implementation of digital technologies by various entities subject to corporate law.

We believe that the digitalization of institutions of corporate law will result in:

the reinterpretation of certain concepts of corporate law, such as corporation and corporate governance;

the improvement of the legal mechanisms of corporate governance following the introduction of $\mathrm{AI}$ into the collegial executive bodies of corporations;

digitalization of corporate assets;

the emergence of new subjects of corporate and other relevant relations. 
Author Contributions: Conceptualization, V.A.L.; methodology, D.R.F.; writing—original draft preparation, D.R.F.; writing-review and editing, V.A.L. All authors have read and agreed to the published version of the manuscript.

Funding: The research was funded by a grant awarded by the Russian Science Foundation (Research Project No. 18-29-16079).

Institutional Review Board Statement: Not applicable.

Informed Consent Statement: Not applicable.

Data Availability Statement: Not applicable.

Conflicts of Interest: The authors declare no conflict of interest.

\section{References}

A System of Blockchain Remote Voting is Developed at St. Petersburg University. 2020. St Petersburg University, October 14. Available online: https:/ / english.spbu.ru/news/3938-a-system-of-blockchain-remote-voting-is-developed-at-st-petersburg-university (accessed on 23 August 2021).

Adizes, Ichak. 2004. Managing Corporate Lifecycles: How Organizations Grow, Age, and Die. Santa Barbara: The Adizes Institute Publishing, $460 \mathrm{p}$.

Alekseev, Roman. 2018. Testing and prospects for the use of blockchain technology in the elections abroad and in Russia. Journal of Political Research 2: 41-48. (In Russian)

Ammous, Saifedean. 2018. The Bitcoin Standard: The Decentralized Alternative to Central Banking. Hoboken: John Wiley \& Sons, vol. XXVIII, 304p.

Announcing Construction IQ Preview, Partner Data Integrations and Other Analytics Capabilities for BIM 360. 2019. February 25. Autodesk. Available online: https:/ / knowledge.autodesk.com/support/bim-360/learn-explore/caas/blog/blogs.autodesk. com/bim360-release-notes/2019/02/26/announcing-construction-iq-preview-partner-data-integrations-and-other-analyticscapabilities-for-bim-360.html?us_oa=dotcom-us\&us_si=66a4d949-252f-4c8f-91c8-eb7c8e3bdb32\&us_st=construction\%20iq\% 20risks (accessed on 20 August 2020).

Arrieta, Alejandro Barredo, Natalia Díaz-Rodríguez, Javier Del Ser, Adrien Bennetot, Siham Tabik, Alberto Barbado, Salvador García, Sergio Gil-López, Daniel Molina, Richard Benjamins, and et al. 2020. Explainable Artificial Intelligence (XAI): Concepts, taxonomies, opportunities and challenges toward responsible AI. Information Fusion 58: 82-115. [CrossRef]

Beck, Roman, Christoph Müller-Bloch, and John Leslie King. 2018. Governance in the blockchain economy: A framework and research agenda. Journal of the Association for Information Systems 19: 1. [CrossRef]

Beck, Roman. 2018. Beyond bitcoin: The rise of blockchain world. Computer 51: 54-58. [CrossRef]

Blemus, Stéphane. 2017. Law and Blockchain: A Legal Perspective on Current Regulatory Trends Worldwide. Revue Trimestrielle de Droit Financier. Corporate Finance and Capital Markets Law Review. December 11. Available online: https://papers.ssrn.com/ sol3/papers.cfm?abstract_id=3080639 (accessed on 23 August 2021).

Blockchain Laws and Regulations. 2020. GLI (23 October 2019). Available online: https:/ /www.globallegalinsights.com/practiceareas/blockchain-laws-and-regulations (accessed on 23 August 2021).

Buterin, Vitalik. 2014. A Next-Generation Smart Contract and Decentralized Application Platform. White Paper 3(37) 36p. Available online: https://blockchainlab.com/pdf/Ethereum_white_paper-a_next_generation_smart_contract_and_decentralized_ application_platform-vitalik-buterin.pdf (accessed on 20 August 2021).

Charan, Amita. 2011. E-Governance A New Dimension of Corporate Governance. July 17. Available online: https://papers.ssrn.com/ sol3/papers.cfm?abstract_id=1641622 (accessed on 15 August 2021).

Chekhovskaya, Svetlana. 2018a. Corporate electronic management and corporate management for electronic corporations: Legal aspects. Entrepreneurial Law 4: 3-11. (In Russian)

Chekhovskaya, Svetlana. 2018b. New Contours of Corporate Law. Entrepreneurial Law 3: 23.

Chowdhury, Niaz. 2019. Bitcoin: The world's first cryptocurrency. In Inside the Blockchain, Bitcoin, and Cryptocurrencies. Boca Raton: Auerbach Publications, pp. 61-89. [CrossRef]

Cihon, Peter, Jonas Schuett, and Seth D. Baum. 2021. Corporate Governance of Artificial Intelligence in the Public Interest. Information 12: 275. [CrossRef]

COVID-19: “Cura Italia” Decree Enacted. 2020. March 18. Baker McKenzie. Available online: https://www.bakermckenzie.com/en/ insight/publications/2020/03/covid19-cura-italia-decree-enacted (accessed on 27 August 2021).

Danaher, John, Michael J. Hogan, Chris Noone, Rónán Kennedy, Anthony Behan, Aisling De Paor, Heike Felzmann, Muki Haklay, Su-Ming Khoo, John Morison, and et al. 2017. Algorithmic governance: Developing a research agenda through the power of collective intelligence. Big Data \& Society 4: 2053951717726554. [CrossRef]

De Filippi, Primavera, and Aaron Wright. 2018. Blockchain and the Law: The Rule of Code. Cambridge: Harvard University Press, 312p.

Deep Knowledge Ventures: Redefining Investment. 2021. May 1. Available online: https:/ / deepknowledgeventures.com (accessed on 25 August 2021). 
Dhillon, Vikram, David Metcalf, and Max Hooper. 2017. The hyperledger project. In Blockchain Enabled Applications. Berkeley: Apress, pp. 139-49.

Dignam, Alan. 2020. Artificial intelligence, tech corporate governance and the public interest regulatory response. Cambridge Journal of Regions, Economy and Society 13: 37-54. [CrossRef]

Dolinskaya, Vladimira. 2006. Corporate Law: Main Provisions and Trends. Moscow: Wolters Kluwer, 736p.

Domingos, Pedro. 2015. The Master Algorithm: How the Quest for the Ultimate Learning Machine Will Remake Our World. New York: Basic Books, 354p.

Egorova, Maria, Vladimir Belykh, and Stephanie Reshetnikova. 2019. The Blockchain Technology: Application Prospects and Importance for the Development of Information-Oriented Society. Lawyer 7: 4-9. [CrossRef]

Erel, Isil, Lea H. Stern, Chenhao Tan, and Michael S. Weisbach. 2018. Selecting Directors Using Machine Learning. NBER Working Paper (24435). Available online: https:/ / www.nber.org/papers/w24435.pdf (accessed on 25 August 2021).

Faqir, Youssef, Javier Arroyo, and Samer Hassa. 2020. An Overview of Decentralized Autonomous Organizations on the Blockchain. Paper presented at the 16th International Symposium on Open Collaboration, New York, NY, USA, August 11. Available online: https:/ / eprints.ucm.es/id/eprint/62273/1/os20-paper-a11-el-faqir.pdf (accessed on 23 August 2021).

Feijóo, Claudio, Youngsun Kwon, Johannes M. Bauer, Erik Bohlin, Bronwyn Howell, Rekha Jain, Petrus Potgieter, Khuong Vu, Jason Whalley, and Jun Xia. 2020. Harnessing artificial intelligence (AI) to increase wellbeing for all: The case for a new technology diplomacy. Telecommunications Policy 44: 101998. [CrossRef] [PubMed]

Fenwick, Mark, and Erik P. Vermeulen. 2019. Technology and corporate governance: Blockchain, crypto, and artificial intelligence. Texas Journal of Business Law 48: 1-15. [CrossRef]

Fersht, Phil, and James R. Slaby. 2012. Robotic Automation Emerges as a Threat to Traditional Low-Cost Outsourcing. Sourcing Security \& Risk Strategies. HfS Research Ltd. Available online: https://www.horsesforsources.com/wp-content/uploads/2016/06/RS-12 10_Robotic-automation-emerges-as-a-threat-060516.pdf (accessed on 12 August 2021).

Feyzrakhmanova, Daria. 2020a. Corporate Conflicts and Legal Means of Their Resolution. Ph.D. dissertation, Kutafin Moscow State Law University, Moscow, Russia; 245p. Unpublished.

Feyzrakhmanova, Daria. 2020b. Distributed Ledger Technology. Public Information Registers. In Digital Economy: The Conceptual Bases of Legal Regulation of Business in Russia: Monograph. Edited by Laptev Vasiliy and Tarasenko Olga. Moscow: Prospekt, pp. 213-18.

Fontenot, Lisa A. 2018. Public company virtual-only annual meetings. The Business Lawyer 73: 35-51. Available online: https:/ / www.gibsondunn.com/wp-content/uploads/2018/01/Fontenot-Public-Company-Virtual-Only-Annual-MeetingsABA-Journal-Jan-2018.pdf (accessed on 1 August 2021).

Franklin, Stan. 2007. A foundational architecture for artificial general intelligence. In Advances in Artificial General Intelligence: Concepts, Architectures and Algorithms. Edited by Ben Goertzel and Pei Wang. Frontiers in Artificial Intelligence and Applications Series. Amsterdam: IOS Press, vol. 157, pp. 36-54.

Gandía, Juan. 2005. Corporate E-Governance Disclosure in the Digital Age: An Empirical Study of Spanish Listed Companies. May 2004. Available online: https:/ / papers.ssrn.com/sol3/papers.cfm?abstract_id=531182 (accessed on 15 July 2021).

Gao, Huasheng, Jun Huang, and Tianshu Zhang. 2020. Can online annual general meetings increase shareholders' participation in corporate governance? Financial Management 49. Available online: https://doi.org/10.1111/fima.12301 (accessed on 1 August 2021). [CrossRef]

Cloverleaf: Coaching for Everyone. 2021. May 10. Available online: https:/ / cloverleaf.me (accessed on 23 August 2021).

Goertzel, Ben. 2016. The AGI revolution: An inside view of the rise of Artificial General Intelligence. Los Angeles: Humanity+ Press, 612p.

Gutnikov, Oleg, and Sergey Sinitsyn. 2019. The Value and Content of Corporate Statutes at the Present Stage: New Approaches in Terms of Digitalization. Law 3: 157-46.

Gutnikov, Oleg. 2020. Corporate Law Development Trends at the Present Time. Journal of Russian Law 8: 73-59. [CrossRef]

Hsieh, Ying-Ying, Jean-Philippe Vergne, Philip Anderson, Karim Lakhani, and Markus Reitzig. 2018. Bitcoin and the rise of decentralized autonomous organizations. Journal of Organization Design 7: 1-16. [CrossRef]

Jentzsch, Christoph. 2017. Decentralized Autonomous Organization to Automate Governance. White paper. November. Available online: https:/ / lawofthelevel.lexblogplatformthree.com/wp-content/uploads/sites/187/2017/07/WhitePaper-1.pdf (accessed on 23 August 2021).

Kharitonova, Yulia. 2014. Corporate Governance and the Duality of Law. Entrepreneurial Law. Law and Business (Suppl. S2): 54-59.

Kharitonova, Yulia. 2018. The Legal Effect of Formalization of Intellectual Property Rights through the Use of Distributed Ledger Technology. Law and Economics 1: 15-21.

Laptev, Vasiliy. 2018. Digital Assets as Objects of the Civil Rights. Legal Science and Practice: Bulletin of the Nizhny Novgorod Academy of the Ministry of Internal Affairs of Russia 2: 199-204.

Laptev, Vasiliy. 2019. Prospects of Blockchain Technology Application to Corporate Registers for the Russian Business. Entrepreneurial Law 3: 28-23. [CrossRef]

Laptev, Vladimir. 1969. The Subject Matter and System of Economic Law. Moscow: Iuridicheskaia Literature. (In Russian)

Longe, Brian. 2017. AST Completes Successful Pilot of Blockchain-Based Solution for Proxy Voting, Processing at Volumes Simulating the Largest Proxy Campaigns. Businesswire. December 13. Available online: https://www.businesswire.com/news/home/20 171213005230 /en / AST-Completes-Successful-Pilot-of-Blockchain-based-Solution-for-Proxy-Voting-Processing-at-VolumesSimulating-the-Largest-Proxy-Campaigns (accessed on 13 September 2021). 
Lomakin, Dmitriy. 1997. Corporate Legal Relation. Moscow: Spark, 186p.

Meet the Chat Bot Ivan from Project Practice. 2018. February 9. Project Practice. Available online: https://pmpractice.ru/news/2018 /3648 (accessed on 25 August 2021).

Mellon, Jonathan, Tiago Peixoto, and Fredrik M. Sjoberg. 2017. Does online voting change the outcome? Evidence from a multi-mode public policy referendum. Electoral Studies 47: 13-24. [CrossRef]

Moll, Jodie, and Ogan Yigitbasioglu. 2019. The role of internet-related technologies in shaping the work of accountants: New directions for accounting research. The British Accounting Review 51: 100833. [CrossRef]

Möslein, Florian. 2018. Robots in the Boardroom: Artificial Intelligence and Corporate Law. In Research Handbook on the Law of Artificial Intelligence. Edited by Woodrow Barfield and Ugo Pagallo. Cheltenham: Edward Elgar Publishing. Available online: https:/ / ssrn.com/abstract=3037403 (accessed on 20 August 2021).

Náñez Alonso, Sergio Luis, Javier Jorge-Vázquez, Miguel Ángel Echarte Fernández, and Ricardo Francisco Reier Forradellas. 2021. Cryptocurrency mining from an economic and environmental perspective. Analysis of the most and least sustainable countries. Energies 14: 4254. [CrossRef]

Nasdaq to Deliver Blockchain E-voting Solution to Strate. 2017. November 22. Nasdaq Investor Relations. Available online: http: / /ir.nasdaq.com/releasedetail.cfm?releaseid=1049610 (accessed on 23 August 2021).

Polge, Julien, Jérémy Robert, and Yves Le raon. 2021. Permissioned blockchain frameworks in the industry: A comparison. ICT Express 7: 229-33. Available online: https:/ /www.sciencedirect.com/science/article/pii/S2405959520301909?via\%3Dihub (accessed on 23 August 2021).

Sannikova, Larisa. 2019. Blockchain in Corporate Governance: Challenges and Opportunities. Law and Economics 4: 27-36.

Sharma, J. P., Sunaina Kanojia, and Shasta Gupta. 2018. An empirical evaluation of legislative reforms for e-corporate governance in Indian companies. Australasian Accounting Business and Finance Journal 12: 29-45. [CrossRef]

Shukla, Shalini, A. N. Thasmiya, D. O. Shashank, and H. R. Mamatha. 2018. Online Voting Application Using Ethereum Blockchain. Paper presented at the 2018 International Conference on Advances in Computing, Communications and Informatics (ICACCI), Bangalore, India, September 19-22. New York: IEEE.

Singh, Madhusudan, and Shiho Kim. 2019. Blockchain technology for decentralized autonomous organizations. Advances in Computers 115: 115-40. [CrossRef]

Starbucks Will Host the Annual Meeting of Shareholders Virtually Because of Coronavirus. 2020. March 4. Vedomosti. Available online: https:/ / www.vedomosti.ru/business/news/2020/03/04/824468-starbucks-godovoe-sobranie (accessed on 1 August 2021).

Sukhanov, Yevgeny. 2014. Comparative Corporate Law. Moscow: Statut, p. 684.

The New Digital Nation. n.d. Republic of Estonia E-Residency. Available online: https:/ /e-resident.gov.ee (accessed on 21 July 2021). Tolstoy, Yuri K. 1959. On the Theory of Legal Relations. Leningrad: Publishing House of Leningrad State University. (In Russian)

Toots, Maarja, Tarmo Kalvet, and Robert Krimmer. 2016. Success in eVoting-Success in eDemocracy? The Estonian Paradox. Paper presented at the 8th International Conference on electronic participation (ePart), Guimarães, Portugal, September 5-8, Lecture Notes in Computer Science. Chem: Springer, vol. 9821, pp. 55-66. Available online: https://hal.inria.fr/hal-01637228/document (accessed on 1 August 2021). (In Russian)

Trubochkina, Nadezhda Konstantinovna, and Savva Konstantinovich Poliakov. 2019. The concept of electronic voting based on blockchain. Information Technologies 25: 75-85. (In Russian) [CrossRef]

Vaypan, Viktor. 2017. Fundamentals of Legal Regulation of the Digital Economy. Law and Economics 11: 18-25.

Vermeulen, Eric. 2015. Corporate Governance in a Networked Age, 50 Wake Forest Law Review 711. August 10. Available online: http:/ / papers.ssrn.com/sol3/papers.cfm?abstract_id=2641441 (accessed on 15 July 2021).

Virtual Shareholder Meeting, Broadridge. 2021. May 1. Available online: https://www.broadridge.com/financial-services/corporateissuer/issuer/simplify-the-annual-meeting-process/virtual-shareholder-meeting? (accessed on 1 September 2021).

VTB Registar. 2021. Available online: https://www.vtbreg.ru/elektronnoe-golosovanie/ (accessed on 12 August 2021).

Yang, Xuechao, Xun Yi, Surya Nepal, Andrei Kelarev, and Fengling Han. 2018. A secure verifiable ranked choice online voting system based on homomorphic encryption. IEEE Access 6: 20506-19. [CrossRef]

Yankovskiy, Roman, and Sergey Yendutkin. 2020. Corporate Governance in the Near Future: Decentralized Companies Ruled by Algorithms? In The National Report on Corporate Governance. Edited by Porshakov Sergey. Moscow: The National Council on Corporate Governance, vol. XII, pp. 235-36.

Yermack, David. 2017. Corporate Governance and Blockchains. Review of Finance 7: 31-37. Available online: https://papers.ssrn.com/ sol3 / papers.cfm?abstract_id=2703207 (accessed on 23 August 2021). [CrossRef]

Zamir, Nasim, Arian Gholami, Yasmin Jajarmi, Nicholas L. Jackson Chornenki, Ameen Patel, and Kelly L. Dore. 2019. Assessing the quality of evidence presented at annual general meetings: A 5-year retrospective study. Journal of Continuing Education in the Health Professions 39: 152-57. [CrossRef] 